\title{
OPTIMALISASI PROSES KOMPUTASI PELEBARAN PITA FREKUENSI DATA SEISMIK REFLEKSI BERBASIS INVERSI BERESOLUSI TINGGI UNTUK PENAFSIRAN STRATIGRAFI SEISMIK
}

\author{
Ruhul Firdaus ${ }^{1}$, Gestin Mey Ekawati ${ }^{1}$ \\ 1 Institut Teknologi Sumatera \\ (ITERA)
}

\begin{abstract}
:
Resolution capability of seismic reflection data is becoming more interesting topic to discuss even for today. Several methods and approximations to attempt bandwidth extension of seismic reflection data have been proposed in wide variety. Among them is a non-stationary reflectivity inversion based on basis pursuit decomposition technique. The need of the method is increasing as it can provide realistic resolution of seismic data. The main advantages of the method are consistancy with log data, good lateral continuity, preserve amplitude and capable in denying artificial reflection feature. Nevertheless, its computational process is very expensive thus most pratitioners tend to avoid the method and look for another method that could serve quicker instead of better results. This paper attempt to propose a set of computational scheme which can be used flexibly for any prospective user to reduce the computational cost of the method.
\end{abstract}

Keyword: computation, optimization, reflectivity inversion, basis pursuit inversion, sparse layer inversion

\section{Pendahuluan}

Eksplorasi migas pada reservoir konvensional maupun non-konvensional sangat bergantung dengan struktur dan karakter batuan yang tercermin pada data seismik refleksi. Pada tahap pengembangan lapangan pun, data seismik masih merupakan data pamungkas bersama-sama data log untuk menemukan cebakan stratigrafi dari suatu reservoir yang sangat tipis. Suatu lapisan yang menarik secara ekonomi dapat diidentifikasi dari data log yang memiliki resolusi yang sangat tinggi $(15 \mathrm{~cm})$ namun seringkali sulit dipetakan karena resolusi seismik yang sangat terbatas (maksimum hanya 10 $\mathrm{m})$.

Kegiatan eksplorasi migas membutuhkan dana dengan jumlah yang besar. Data yang diperoleh dari aktivitas eksplorasi sudah selayaknya digunakan secara optimal untuk mendapatkan informasi bawah permukaan bumi secara maksimal. Proses rekayasa data saat ini sudah tersedia untuk membantu dalam interpretasi stratigrafi reservoir migas konvensional maupun non-konvensional terutama yang berkaitan dengan lapisan yang memiliki ketebalan di bawah kemampuan resolusi seismik. Namun, proses tersebut cenderung mahal secara komputasional sehingga seringkali diabaikan karena dirasa kurang efisien dari sudut pandang manajemen meskipun akan membantu dalam perhitungan cadangan dengan lebih akurat sehingga mengurangi ketidakpastian dalam bisnis migas. Hasil penelitian ini diharapkan dapat menjadikan proses tersebut menjadi lebih efisien sehingga kandungan informasi pada data dapat diekstrak pada kapasitas yang lebih tinggi.

Basis Pursuit Inversion (BPI) pertama kali diperkenalkan oleh Zhang \& Castagna pada tahun 2011. Semenjak itu, Zhang telah mengeluarkan beberapa studi BPI lanjutan. Pada tahun 2012, Zhang et al. melakukan studi kalibrasi BPI dengan Very Fast Simulated Annealing (FVSA). Hasilnya menunjukkan bahwa BPI dapat dianggap setara dengan metoda statistik VFSA sehingga teknik inversi deterministik BPI dapat meningkatkan keyakinan dalam interpretasi. Pengembangan berikutnya dikeluarkan oleh Zhang et al. pada tahun 2013 tentang implementasi BPI pada data prestack. Pengembangan metoda juga dilakukan kearah inversi non-stasioner untuk mengakomodasi inversi dengan menggunakan beberapa wavelet secara simultan namun masih terkendala dengan biaya komputasi yang masih tinggi (Firdaus, 2014). Paper ini mencoba untuk menawarkan skema komputasi yang lebih efisien. 
Batas lapisan batuan bawah permukaan direpresentasikan oleh koefisien reflektivitas. Namun, koefisien reflektivitas $(\mathrm{RC})$ tersamarkan akibat sempitnya bandwidth gelombang sumber (wavelet) dibandingkan bandwidth RC, sehingga batas antar lapisan sulit dibedakan (resolusi rendah). Metoda "dekonvolusi" biasa digunakan untuk mengkompres wavelet atau bahkan menghilangkan efek wavelet sama sekali sehingga dapat meningkatkan resolusi temporal data seismik. Peningkatan resolusi vertikal ini tercermin pula dalam domain spektrum berupa perluasan rentang spektrum (bandwidth) data seismik. Resolusi menyatakan seberapa dekat dua batas lapisan sehingga masih dapat dibedakan. Peningkatan resolusi temporal berarti meningkatkan daya pisah antar lapisan secara vertikal.

\subsection{Teori}

\section{Metoda}

Teknik seismik inversi pada prinspipnya adalah metoda dekonvolusi. Proses inversi data seismik adalah suatu proses balik untuk mendapatkan kembali nilai reflektivitas bumi dari trace seismik yang terekam sebagai respon dari impuls (wavelet) yang dibangkitkan sumber. Tujuan inversi seismik adalah menghilangkan efek wavelet pada rekaman seismik sehingga otomatis akan meningkatkan resolusi vertikal data seismik.

Inversi data seismik merupakan teori dan praktik yang populer di geofisika seismik reservoir. Inversi non-stasioner menjadi relevan pula akibat fenomena perubahan wavelet sering ditemukan dalam data (Firdaus, dkk., 2014). Cara yang paling sederhana untuk melakukan dekonvolusi (inversi) adalah dengan menerapkan inversi linear (direct inversion). Inversi linear akan memberikan hasil yang baik dengan resolusi tinggi hanya jika matriks kernel bersifat ortogonal. Kriteria ini dapat dipenuhi hanya jika kita memiliki hubungan linier yang eksak antara data dan model. Sayangnya, secara praktik, kriteria ini sulit dipenuhi. Tantangan utamanya adalah:

a) rendahnya kualitas data seismik

b) ekstraksi wavelet yang tidak akurat

c) adanya error karena perbedaan antara asumsi model konvolusional dengan realita sebenarnya Cara lain yang lebih baik untuk melakukan inversi adalah dengan metoda optimasi non-linear model RC dengan pendekatan linear atau dengan metoda statistik (optimasi global). Pengalaman membuktikan bahwa inversi non-linear jauh lebih bisa mendekati keadaan real dibandingkan inversi linear, namun hasil inversinya sangat bergantung pada pemilihan model awal. Kesalahan penentuan model awal dapat mengantarkan pada minimum lokal.

Metoda statistik dilahirkan untuk mencari solusi optimum global yang sangat sulit ditemukan menggunakan metoda inversi non-linear dengan pendekatan linear. Agar tidak terjebak dengan minimum lokal, metoda ini tidak menggunakan gradien fungsi objektif melainkan langsung mengevaluasi fungsi objektif itu sendiri. Secara umum, metoda ini bermasalah dengan nonuniqueness. Keunggulan inversi stokastik adalah dapat menyajikan solusi inversi yang terkondisi secara geologi lengkap dengan ukuran probabilitasnya.

Walaupun telah banyak metoda yang disarankan, kebutuhan praktikal masih belum dapat dipenuhi seutuhnya. Penggunaan metoda yang berbeda akan memberikan hasil yang berbeda pula dan bisa mengantar pada nilai RC yang salah. Kekurangan norm Euclidean dalam hal sparsity dan teknik stokastik dalam hal non-uniqueness diharapkan dapat diatasi dengan penggunaan norm yang berdasarkan sparsity. Pada akhirnya, perlu dipertimbangkan penggunaan konsep jarak sparsity $\left(\right.$ norm $-l_{0}$ ) atau yang ekuivalen dengan sparsity seperti konsep jarak nilai absolut (norm $-l_{1}$ ) untuk merepresentasikan karakteristik $\mathrm{RC}$ yang sparse. Dengan minimalisasi norm $-l_{1}$ kita pun dapat mencapai minimum global sebagaimana pada teknik stokastik.

BPI mengadaptasi konsep representasi sinyal sparse dengan menyusun Dictionary berupa kombinasi pasangan reflektivitas ganjil dan genap sebagai representasi dasar bagi reflektor. Inversi basis pursuit (BPI) yang diusulkan oleh Zhang \& Castagna (2011) memanfaatkan konsep dan algoritma BPDN untuk mendekomposisi data seismik dengan menggunakan Dictionary berupa waveform nonortogonal yang tersusun dari respon seismik terhadap lapisan tipis berkonfigurasi genap ("even") dan ganjil ("odd"). RC dibentuk dengan menjumlahkan pasangan $\mathrm{RC}$ yang digeser dan dikali bilangan skalar dengan translasi dan koefisien yang dihasilkan metoda basis pursuit. Permasalahan inversinya dituliskan dalam bentuk formulasi kasus representasi sinyal sparse: $\boldsymbol{\Phi \mathbf { x }}=\mathbf{y}$, dimana $\boldsymbol{\Phi}$ adalah kumpulan semua kemungkinan 
bentuk waveform, $\boldsymbol{x}$ adalah koefisien untuk setiap jenis waveform, dan $\boldsymbol{y}$ adalah data seismik. Formulasi representasi sparse di atas mengantarkan kita pada masalah optimasi untuk menyelesaikan persamaan linear sistem under-determined. Dengan menyusun semua atom dalam Dictionary besar $\boldsymbol{\Phi}$ , kita ingin mencari koefisien $\boldsymbol{x}$ yang merupakan solusi paling optimal sekaligus paling sparse untuk merepresentasikan data seismik yang terekam $\boldsymbol{y}$ melalui pernyataan optimasi yang diberikan pada persamaan (1) dan (2):

$$
\min \|y-\Phi x\|_{2}+\lambda\|x\|_{1}
$$

atau

$$
\min \|x\|_{1} \text { subject to }\|y-\Phi x\|_{2} \leq \delta
$$

BPI tidak memerlukan model awal karena langsung mengaitkan data dengan informasi a priori. Selain itu, BPI menggunakan optimasi norm $l_{1}$ sehingga dapat mencari konfigurasi pasangan reflektivitas genap dan ganjil secara optimal, ini mengantarkan pada solusi yang sparse. Keunggulan BPI berkaitan erat dengan fakta bahwa BP menemukan satu solusi global yang optimal. Dengan demikian, inversi yang dihasilkan menjadi sparse layer dengan resolusi yang sangat baik. Zhang \& Castagna (2011) memanfaatkan penyelesaian persamaan primal dan dual dari program linear yang diusulkan oleh Chen (2001). Namun, saat ini ada banyak pendekatan lain untuk menyelesaikan masalah optimasi norm $l_{1}$. Kita bisa mengklasifikasi algoritma yang ada saat ini dalam enam kelas yang representatif seperti yang dilakukan Yang et al. (2010): Linear Programing, Gradient Projection, Augmented Lagrange Multiplier, Iterative Shrinkage-Thresholding, Homotopy, dan Proximal Gradient. Linear Programing merupakan solusi klasik untuk problem minimasi $l_{1}$, memiliki ketelitian tinggi namun kurang robust dalam mencapai kekonvergenan. Kelima algoritma lainnya disusun untuk mengatasi masalah yang ada pada algoritma Linear Programming. Gradient Projection mencari representasi sparse dari $x$ dengan mengikuti arah gradient tertentu sehingga dapat mempercepat proses konvergensi. Algoritma Augmented Lagrange Multiplier sangat popular dalam pemrograman konveks. Ide dasarnya adalah untuk mengeliminasi konstrain ekualitas dengan menambahkan terminologi penalty pada fungsi objektif. Iterative ShrinkageThresholding menggunakan operasi matriks sederhana seperti aljabar vektor dan pekalian matriksvektor, berbeda dengan beberapa metoda sebelumnya yang melibatkan operasi matriks yang lebih rumit seperti faktorisasi dan penyelesaian least-square linear. Homotopy memanfaatkan fakta matematis bahwa terdapat aliran constraint dari $l_{2}$ menjadi $l_{1}$ seiring peningkatan $\lambda$ (faktor pengali Lagrange) dengan menentukan "breakpoints" yang mengantarkan pada perubahan support sehingga pencarian koefisien tak-nol yang baru menjadi lebih efisien. Proximal Gradient mewakili algoritma jenis lain. Prinsip dibalik algoritma ini adalah mengganti fungsi objektif dimana suku pertama dari persamaan regularisasi adalah fungsi konveks yang smooth dengan gradien kontinyu Lipschitz dan suku keduanya adalah fungsi konveks kontinyu. Untuk mewakili masing-masing kelas algoritma tersebut, satu solver dipilih untuk kemudian dibandingkan performanya jika dihadapkan dengan masalah-masalah yang biasa ditemukan dalam seismik inversi terkait kualitas data, kesalahan estimasi wavelet dan kemampuan resolusi.

\subsection{Lingkungan eksperimen}

Lingkungan komputasi yang digunakan adalah: Intel(R) Core(TM) i7-2600 CPU @ 3.40GHz 4.10 GHz. Pada tahap ini dilakukan uji coba metoda terhadap masalah yang sudah diketahui solusinya, dilakukan dengan tiga langkah: pemodelan kedepan dengan wavelet dan reflektivitas yang diketahui; inversi dengan berbagai algoritma BPI; dan perbandingan hasil inversi dengan model reflektivitas menggunakan korelasi silang. Setiap langkah simulasi tersebut diterapkan pada dua kasus berbeda: kasus reflektivitas jarang ("sparse") dan rapat ("dense") seperti pada Gambar 1. Pengujian dilakukan dengan menggunakan model "sparse" dan "dense" bebas noise dan wavelet diketahui dengan pasti. Tujuan eksperimen ini adalah : (1) Melihat konsistensi parameter yang kami tetapkan, (2) Membandingkan pengaruh parameter akurasi terhadap kasus data sparse dan dense, (3) Studi perbandingan antar metoda dikaitkan dengan parameter akurasi yang dipilih. 

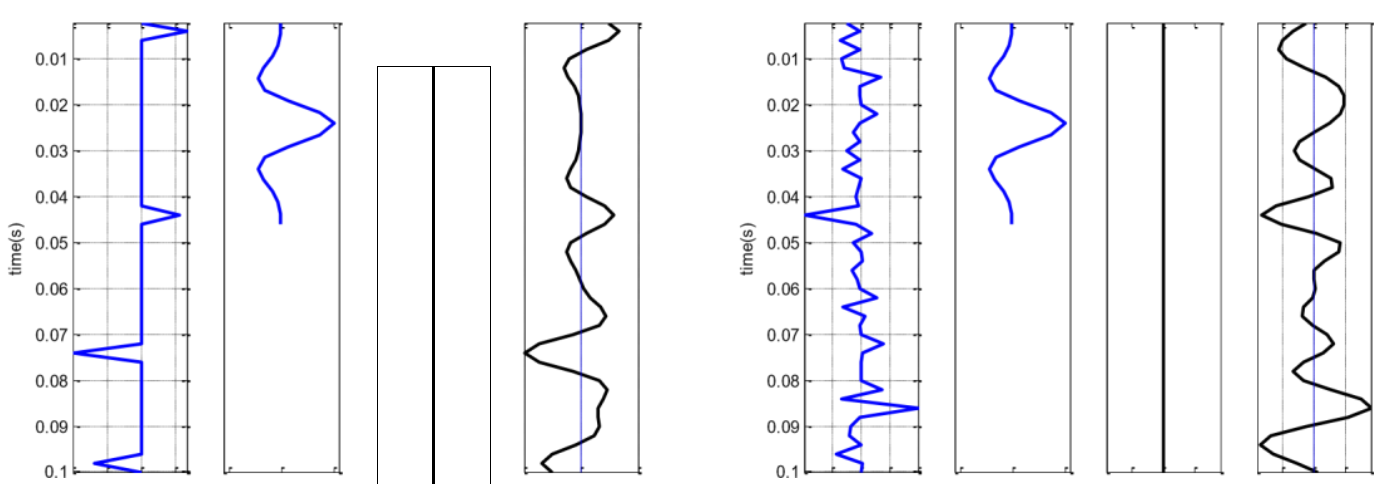

$-1-0.500 .5-101-101-101-0.500 .51-101-0.500 .5-0.500 .5 R(t) w(t) n(t) S(t) R(t) w(t) n(t) S(t)$

Gambar 1 Pemodelan eksperimen untuk kasus reflektivitas "sparse” (atas) dan "dense" (bawah).

\subsection{Perbandingan performa berbagai algoritma BPI}

\section{Hasil dan Pembahasan}

Parameter yang digunakan pada setiap metoda berbeda-beda namun diatur sedemikian rupa agar mencapai kriteria super-resolve. Pengkondisian dasar adalah toleransi error diatur agar dapat setara dengan parameter akurasi. Selanjutnya, parameterisasi yang disisakan hanyalah parameter yang menyatakan tingkat akurasi optimasi yang terkait langsung dengan level noise. Hasil pada Gambar 2 memperlihatkan konsistensi parameter yang penulis tentukan sehingga satu sama lain dapat dibandingkan secara proporsional. Selanjutnya parameter yang merupakan hasil elaborasi parameter regularisasi dan akurasi ini kami beri simbol delta. Studi kami menunjukkan bahwa keseluruhan metoda tersebut saling kompetitif satu sama lain terkait kualitas hasil yang diberikan hanya saja metoda terbaru lebih unggul dari aspek kecepatan komputasi sehingga menjadi layak digunakan pada data yang panjang seperti pada implementasi pelebaran pita frekuensi. Pemilihan parameter akurasi (regularisasi) dilakukan dengan mempertimbangkan: (1) Kualitas frekuensi data, (2) Tingkat gangguan noise, (3) Akurasi pemilihan wavelet, (4) Sparseness solusi yang diinginkan.
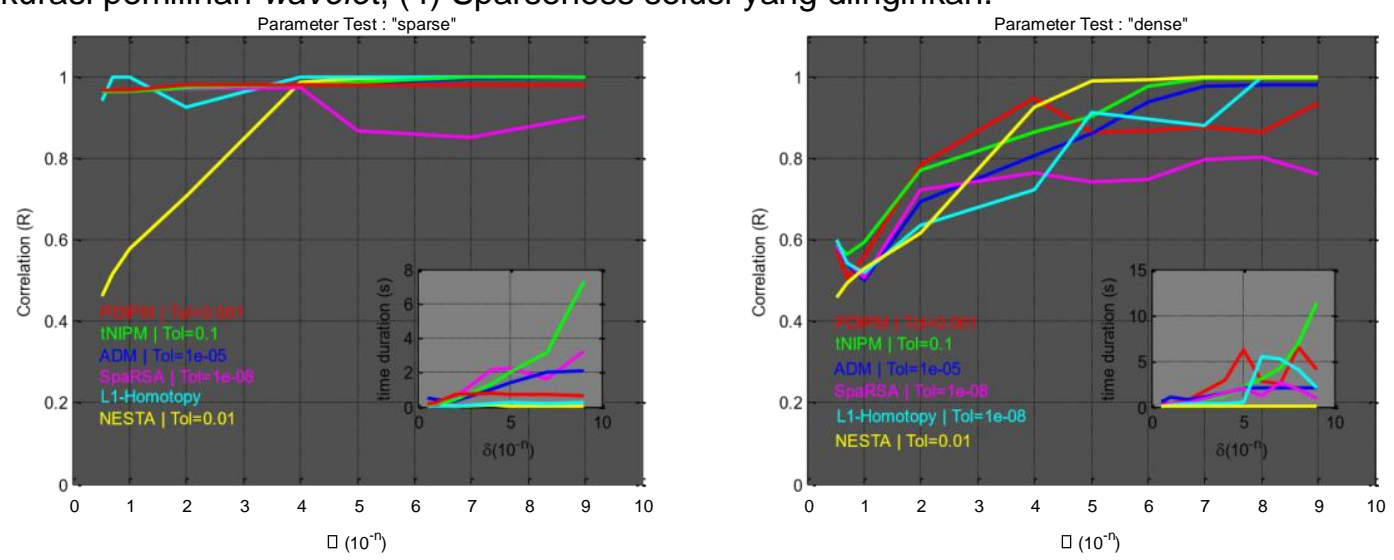

Gambar 2 Hasil simulasi pemilihan parameter.

\subsection{Optimalisasi BPI}

Deret reflektivitas diasumsikan memiliki karakteristik dasar yang sparse, namun dalam praktiknya, deret reflektivitas bersifat "dense". Karena itu, Dictionary yang hanya mencakup tepi wedge saja dirasa sudah cukup. Dengan mengefisienkan ukuran Dictionary, maka kita dapat mengurangi beban komputasi dan memiliki keleluasan lebih dalam memodelkan berbagai asumsi wavelet pada implementasi di kasus inversi non-stasioner.

Hasil pada Gambar 3 menunjukkan bahwa dengan melakukan efisiensi Dictionary, kita memperoleh beberapa keuntungan: waktu yang dibutuhkan dan ukuran problem berkurang; kompleksitas masalah berkurang sehingga proses menjadi lebih stabil; dan memberikan hasil dengan kualitas yang sedikit 
lebih baik. Beberapa keuntungan ini diperoleh terutama karena berkurangnya kompleksitas sistem inversi.
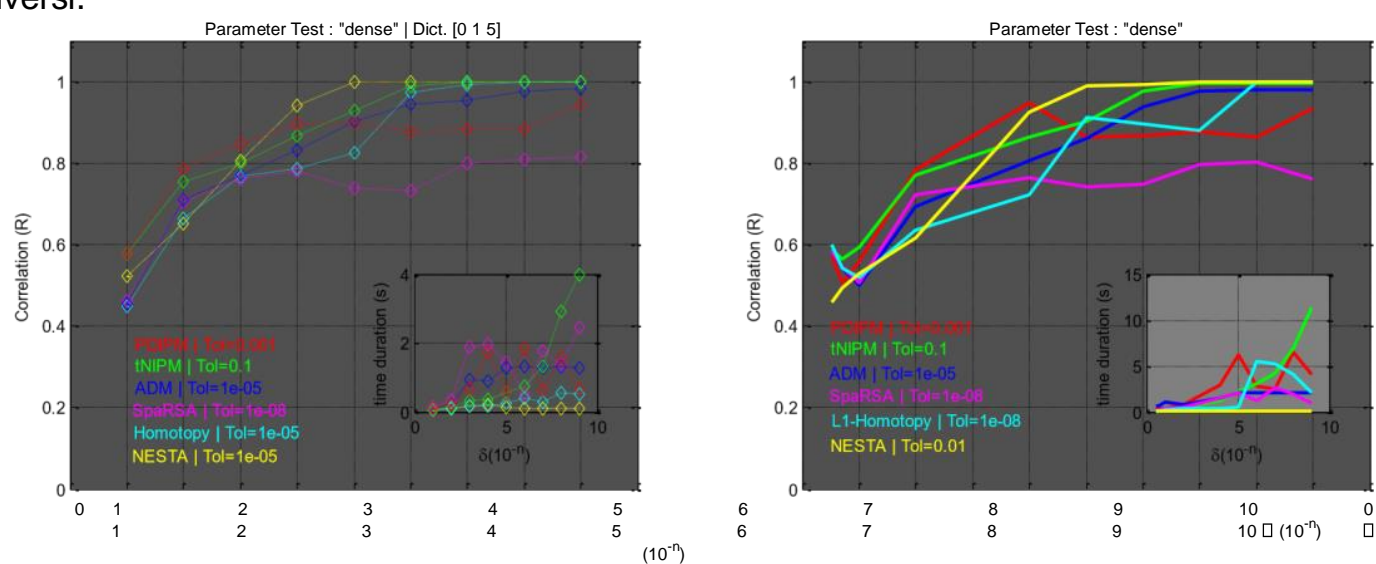

Gambar 3 Efisiensi Dictionary untuk kasus "dense". Performa BPI dengan ketebalan pasangan reflektivitas maksimum dalam Dictionary adalah 5dt (kiri) memiliki kualitas hasil inversi yang setara dengan Dictionary yang utuh $1 \lambda$ (kanan).

Proses BPI dapat pula dipartisi secara hari-hati dengan mengatur kelengkapan Dictionary setiap partisi agar bersesuaian persis dengan Dictionary global yang diterapkan tanpa partisi. Ini berkaitan dengan sifat Dictionary yang time-adaptive. Untuk menghindari aliasing, perlu ditambahkan data sepanjang $1 \lambda$ baik di bagian atas maupun bawah dari target yang sedang dievaluasi. Hasil eksperimen (Gambar 4) memperlihatkan bahwa dengan melakukan partisi proses BPI, prosesnya akan berjalan lebih cepat tanpa mengakibatkan pengurangan korelasi.

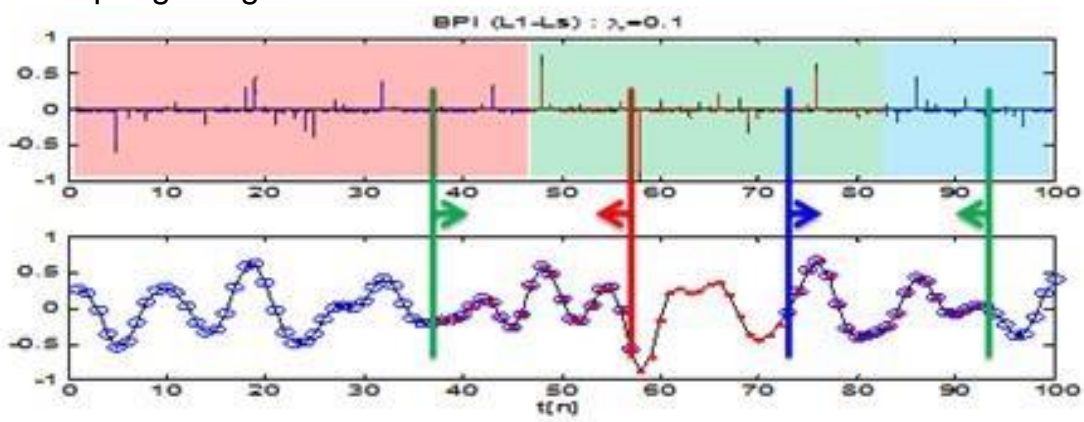

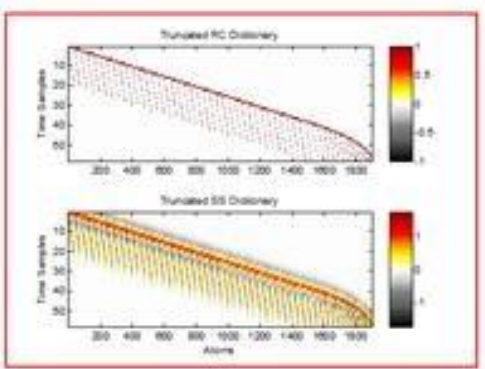

Core 1

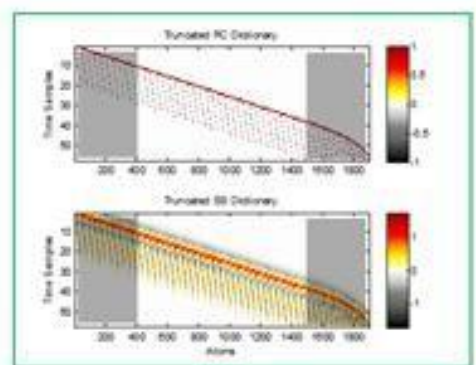

Core 2

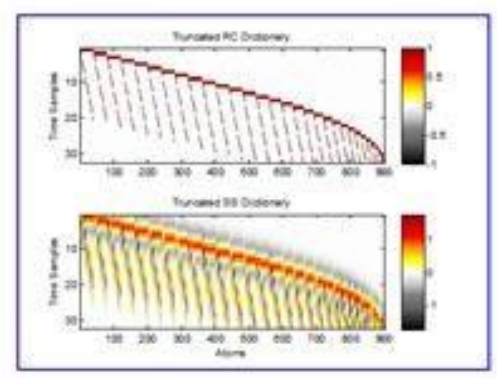

Core 3

Gambar 4 llustrasi skema partisi dan paralelisasi proses komputasi inversi basis pursuit untuk dikerjakan oleh 3 (tiga) Prosesor

Proses partisi independen satu sama lain sehingga pada tahap ini dapat diterapkan strategi paralelisasi komputasi. Setiap proses partisi dibebankan kepada satu prosesor sehingga untuk satu jejak seismik yang dipartisi menjadi empat misalnya, dapat dilakukan dengan waktu $1 / 4$ dari yang dibutuhkan sebelum paralelisasi sebagaimana diperlihatkan pada Tabel 1. Nilai peningkatan kecepatan komputasi dapat bervariasi bergantung pada kestabilan mesin, namun adanya peningkatan kecepatan komputasi terlihat nyata pada eksperimen ini. 


\begin{tabular}{|l|l|l|l|}
\hline Algoritma & Original & Partisi & Paralelisasi \\
\hline PDIPM & 5,8 jam & 6 menit & 90 detik \\
\hline tNIPM & 27 menit & 53 detik & 15 detik \\
\hline ADM & 125 detik & 49 detik & 13 detik \\
\hline SpaRSA & 22 menit & 22 detik & 6 detik \\
\hline Homotopy & 7 detik & 82 detik & 10 detik \\
\hline NESTA & 6,8 menit & 18 detik & 5 detik \\
\hline
\end{tabular}

Tabel 1. Perbandingan waktu implementasi algoritma dengan berbagai skema

\subsection{Stratigrafi Seismik}

Permasalahan utama dalam analisis stratigrafi seismik terletak pada masalah terminasi lapisan dan jumlah lapisan yang teresolusi. Kemampuan BPI dalam meresolusi lapisan sangat baik bahkan dapat dikatakan hampir sempurna sebagaimana diperlihatkan pada Gambar 5. Setiap nilai akustik impedansi dapat diestimasikan dengan hampir sempurna. Sehingga dapat dikatakan masalah stratigrafi dapat diselesaikan secara utuh dari segi algoritma inversi. Hal tersebut diperlihatkan pada uji coba inversi akustik impedansi dengan BPI membuat seismik sintetik dari data akustik impedansi sumur.

Kendala utamanya muncul ketika metoda BPI diterapkan pada data real, performa yang diberikan tidak sebagaimana pada uji sintetik. Hal itu dikarenakan faktor kesalahan dalam estimasi wavelet dan kehadiran noise pada data. Sementara dari uji sintetik sebelumnya dapat dikatakan bahwa lebar pita frekuensi data seismik bukan merupakan kendala bagi metoda BPI. Hasil uji data real diperlihatkan pada Gambar 6. Dapat dilihat adanya peningkatan jumlah lapisan terutama pada lapisan yang mengalami tuning. Selain itu ketajaman reflector juga dapat membantu dalam mengatasi ambiguitas antara terminasi lapisan atau conformity yang tipis.

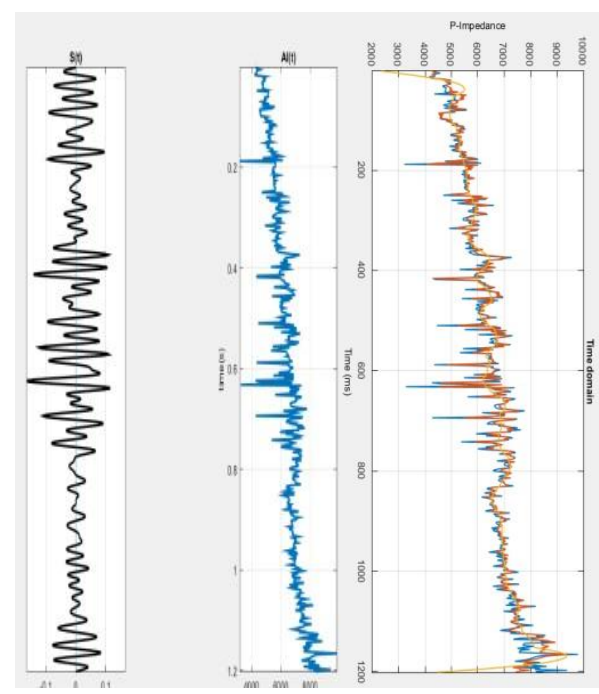

Gambar 5 Akustik Impedansi hasil BPI pada skema ideal, wavelet diketahui. Paling kiri adalah data sintetik pada sumur. Tengah adalah parameter akustik impedansi pada sumur. Paling kanan adalah perbandingan akustik impedansi sebenarnya (biru) dengan estimasi BPI (orange) setelah ditambahkan low-frequency model (kuning) 

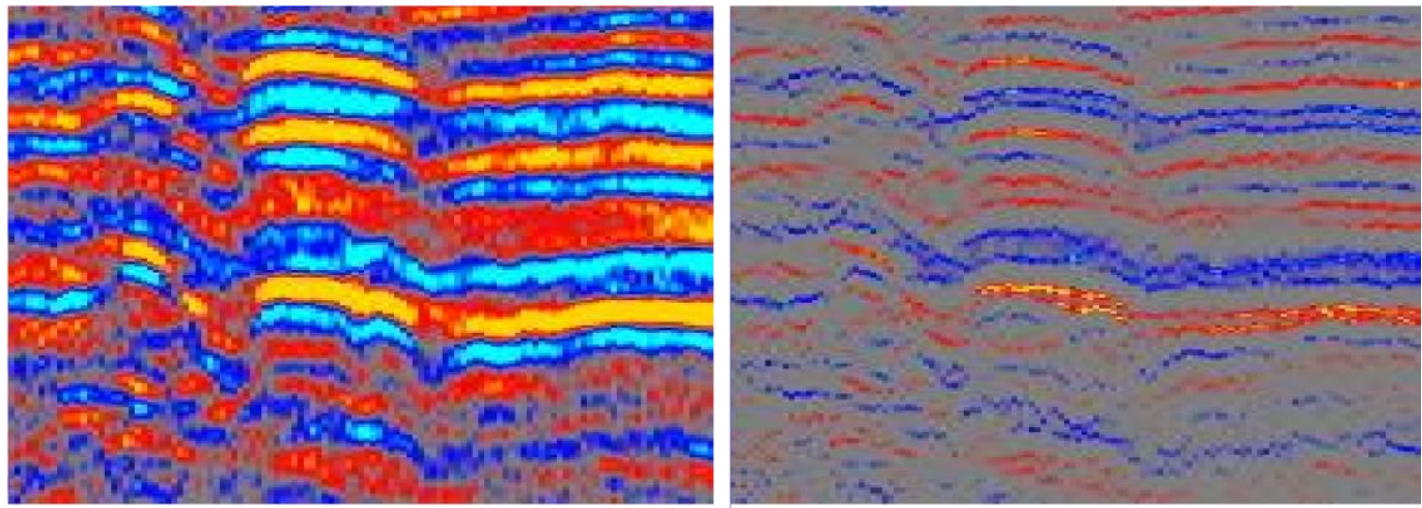

Gambar 6 Reflektivitas BPI (kanan) dibandingkan dengan data real (kiri) dengan wavelet yang diestimasikan secara statistik

\section{Kesimpulan}

Studi kami menunjukkan bahwa keseluruhan metoda optimasi $l_{1}$ saling kompetitif satu sama lain mengenai kualitas hasil yang diberikan. Akan tetapi, metoda terbaru lebih unggul dari aspek kecepatan komputasi sehingga cocok digunakan pada data berukuran besar. Untuk optimasi BPI, kami menyarankan efisiensi Dictionary, mempartisi proses serta melakukan paralelisasi komputasi. Dengan demikian, kecepatan komputasi secara nyata menurun dengan signifikan untuk semua algoritma yang dicoba. Dengan didukung teknologi komputasi paralel, skema ini dapat dikembangkan menjadi skema komputasi paralel dua lapis sehingga proses komputasi menjadi lebih cepat lagi. Dari aspek stratigrafi seismic, inversi BPI dapat mengatasi masalah keterbatasan bandwidth data seismik dalam menganalisis lapisan tipis. Meskipun pengaruh kesalahan estimasi wavelet dan noise masih berpengaruh signifikan, hasil yang diberikan telah memperlihatkan perbaikan dalam hal pemisahan lapisan tuning dan terminasi lapisan.

\section{Penghargaan}

Terima kasih banyak penulis sampaikan kepada LP3 Institut Teknologi Sumatera yang telah mendanai penelitian ini. Penghargaan sebesar-besarnya juga penulis sampaikan kepada Bapak Soni Winardhie, Ph.D. dan Bapak DR. Alfian Bahar atas masukan yang sangat berarti.

\section{Daftar Pustaka}

[1] R. Zhang, and J.P. Castagna, "Seismic sparse-layer reflectivity inversion using basis pursuit decomposition", Geophysics vol. 76, pp. R147-R158, Nov-Dec 2011

[2] R. Zhang, M.K. Sen, S. Phan, and S. Srinivasan, "Stochastic and deterministic seismic inversion methods for thin-bed resolution," Journal of Geophysics and Engineering, vol. 9, pp. 611-618, September 2012

[3] R. Zhang, M.K. Sen, and S. Srinivasan, "A prestack basis pursuit seismic inversion," Geophysics, vol. 78, pp. R1-R11, January 2013 [4] R. Firdaus, "Inversi reflektivitas nonstasioner dengan metoda dekomposisi basis pursuit," M.S. thesis, Institut Teknologi Bandung, Indonesia, 2014

[5] S. S. Chen, D. L. Donoho, and M. A. Saunders, "Atomic decomposition by basis pursuit," Society for Industrial and Applied Mathematics Review, vol. 43, pp. 129-159, February 2001

[6] A. Yang, A. Ganesh, S. Sastry, and Y. Ma, "Fast I1-minimization algorithms and an application in robust face recognition: a review," in Proceedings of the International Conference on Image Processing, 2010 